\title{
Racial admixture of Apis mellifera in Tasmania, Australia: similarities and differences with natural hybrid zones in Europe
}

\author{
BENJAMIN P. OLDROYD $\dagger^{*}$, JEAN-MARIE CORNUET ††, DARRYL ROWE†, THOMAS E. \\ RINDERER \& ROSS H. CROZIER $\dagger$ \\ $\dagger$ School of Genetics and Human Variation, La Trobe University, Bundoora, Vic 3083, Australia, $\ddagger$ Laboratoire de \\ Neurobiologie Comparèe des Invertébrès, INRA-CNRS URA 1190, La Guyonnerie, B.P. 23, 91440 Bures-sur-Yvette, \\ France and $\S$ Honey-Bee Breeding, Genetics and Physiology Research Laboratory, USDA-ARS, 1157 Ben Hur Road, \\ Baton Rouge, LA 70820, U.S.A.
}

\begin{abstract}
Feral and domesticated honey bees were collected across the island state of Tasmania, Australia, and typed for malate dehydrogenase and a mitochondrial DNA polymorphism. They were also compared morphometrically with reference specimens of Apis mellifera ligustica and $A . m$. mellifera from Europe. These measures were correlated with temperature and elevation. In warmer coastal regions, the two subspecies readily hybridize and most samples showed evidence of considerable hybridization. In cooler mountain regions, there is much less hybridization, with the $A$. $m$. mellifera subspecies characteristics strongly predominating. There is no evidence for cytonuclear incompatibilities between these subspecies or for clines caused by direct selection. We hypothesize that $A . m$. ligustica and $\mathrm{F}_{1}$ hybrids have lower fitness than $A$. $m$. mellifera in cooler regions, and that there may be assortative mating in cooler regions only. The significance of these results for the understanding of honey bee hybrid zones in Europe is discussed.
\end{abstract}

Keywords: Apis mellifera, cline, hybrid zone, malate dehydrogenase, mitochondrial DNA, morphometrics.

\section{Introduction}

Understanding how two adjoining subspecies maintain their identity is of considerable interest because the phenomenon may represent an early stage of speciation (Barton \& Hewitt, 1985). Two situations have to be considered: (i) when adjoining subspecies have evolved parapatrically, and (ii) when adjoining subspecies have diverged allopatrically but have become reunited by secondary contact. The first case is the normal consequence of genetic drift and selection resulting in genetically distinct populations. The second case is much more interesting as there is the potential for competition between two expanding subspecies which are already genetically distinct. In some cases this may lead to the displacement of one subspecies by the other, the merging of the two (Moore, 1977) or, if speciation has proceeded far enough, a hybrid zone may develop characterized by coincident clines for the

*Correspondence. characters differentiating the two subspecies. Equally fit alleles may diffuse across the hybrid zone. The width of the cline will depend on how recently the contact was made and the rate of dispersal of individuals (Endler, 1977).

If the fitness in $F_{1}$ hybrids of the two subspecies differs from that of parents, a hybrid zone, or tension zone, may become virtually permanent, impeding gene flow between adjoining subspecies for many generations (Moore, 1977; Moore \& Buchanan, 1985). The width of such a zone depends not only on the rate of dispersal, but also on the relative fitness of $F_{1} s$ (Hewitt, 1988). Following Bazykin (1969) the model of Barton \& Hewitt (1985) requires hybrid unfitness (from the breakdown of coadapted gene complexes or abnormalities in chromosomal pairing in $F_{1} s$ ) but no environmental gradient for the maintenance of hybrid zones. In contrast, Moore (1977) and Moore \& Buchanan (1985) show that permanent hybrid zones can result from heterosis in $F_{1} s$, coupled with an environmental gradient in which $F_{1} s$ are fitter than either parent within 
the zone of intermediate ecology between the native ranges of the parental subspecies.

The western honey bee Apis mellifera is native to Europe, Africa and western Asia. This broad geographical distribution has resulted in the evolution of three distinct evolutionary branches: western European (M), northern Mediterranean (C) and African (A). These branches were initially discovered using morphometrics (Ruttner et al., 1978; Ruttner, 1988) and have been largely confirmed by mitochondrial DNA studies (Smith, 1991; Garnery, 1992; Garnery et al., 1992). As defined by morphometrics, these branches represent one to eight subspecies including $A$. $m$. mellifera (branch $\mathrm{M}$ ) and $A$. $m$. ligustica (branch C). In northern Italy, these two subspecies have formed a contact zone which has been well characterized by allozyme and morphometric studies (Cornuet, 1983; Badino et al., 1983, 1984, 1988a,b; Comparini \& Biasiolo, 1991; Nazi, 1992; Meixner et al., 1993). This contact zone provides an ideal system for studying a secondary contact between two formerly allopatric subspecies. Because of the high level of genetic divergence between mellifera and ligustica, there are morphological, mitochondrial and allozyme markers available to discriminate between them (reviewed by Oldroyd et al., 1992). Secondly, these two subspecies have been exported to many places around the world during the past century, providing opportunities to study artificial contact zones in new environments.

Tasmania (Australia) is such a new environment. In 1831, a first Apis mellifera colony was introduced from Great Britain, presumably of the subspecies mellifera. By 1860 , honey bees were apparently feral and widespread throughout the island (Ayton, 1977). The first reputedly 'Italian' $(A$. m. ligustica) bees were introduced to the island more than 50 years later in 1884 (H. Ayton, personal communication). Bees of Italian lineage are used extensively for commercial and amateur beekeeping. Several thousand ligustica queens are imported into the state each year from queen propagation farms in subtropical Queensland and New South Wales, and many more are produced locally. After so many years of extensive propagation of ligustica-type bees, one might expect the extinction of the mellifera type, unless strong selection or barriers to hybridization prevent gene flow between the two populations; and yet Ruttner (1976) reported a population of dark bees from Tarraleah, Tasmania, that are 'unhybridized' $A$. m. mellifera.

Here, we report on the genetic structure of the honey bee population of Tasmania, using morphometrics and malate dehydrogenase as nuclear markers, and mitochondrial DNA RFLPs as cytoplasmic markers. 'Pure' A. m. ligustica and A. m. mellifera are generally identifiable by malate dehydrogenase ( $M d h)$ allele frequencies (Cornuet, 1983) and mt-DNA RFLPs (Garnery, 1992). Studies which simultaneously examine nuclear and cytoplasmic markers (cytonuclear systems) provide the opportunity to obtain insight into the nature of the hybridization process (Arnold, 1993). As clines correlated with environmental temperature have been reported for morphometric characters (Ruttner, 1988; Daly et al., 1991) and Mdh allele frequencies (Nielson et al., 1994) we looked for significant correlations between genetic markers and environmental temperature. By these means, we attempt to determine if the observed clines are environmentally induced or are the result of a contact zone. In the light of these analyses, the coexistence of the two subspecies in Tasmania and in contact zones in Europe are discussed.

\section{Materials and methods}

\section{Field collections}

Collections were made from individual colonies across Tasmania (Fig. 1). Bees were caught outside colonies in sweep nets or by aspiration, or if the colony was in a moveable frame hive, by scraping bees off honey combs. Bees were killed immediately by freezing in liquid nitrogen. For each colony, about half the bees were preserved in liquid nitrogen and half in ethanol. Except for a collection from commercial colonies originating from Mole Creek, all bees were feral. Feral colonies were defined as those that met at least one of the following criteria: (i) colonies in tree hollows (nine colonies); (ii) recently hived swarms that had not been requeened ( 24 colonies); and (iii) colonies in neglected or abandoned apiaries where the owner or apiary inspector stated that there had been no queen replacement by the beekeeper for at least 10 years $(63$ colonies). Up to 12 colonies were sampled at any one site, but more usually three to seven (Fig. 1).

In addition to feral colonies, bees were sampled from 20 colonies at Tarraleah. The apiary was established in 1969 from feral bees from the surrounding eucalyptus forest by L. Slater (Ayton, 1977). Because Ruttner (1976) reported that the morphology of the bees of Tarraleah 'corresponds almost exactly to the original bee from north-west Europe', the area surrounding Mr Slater's apiary has been declared a sanctuary for the preservation of the bees which are thought to be an isolated population of $A$. mellifera mellifera. However, the sanctuary has little legal force and is not geographically isolated. Mr Slater does not undertake any selection or queen production. The bees interbreed freely with wild colonies which are 


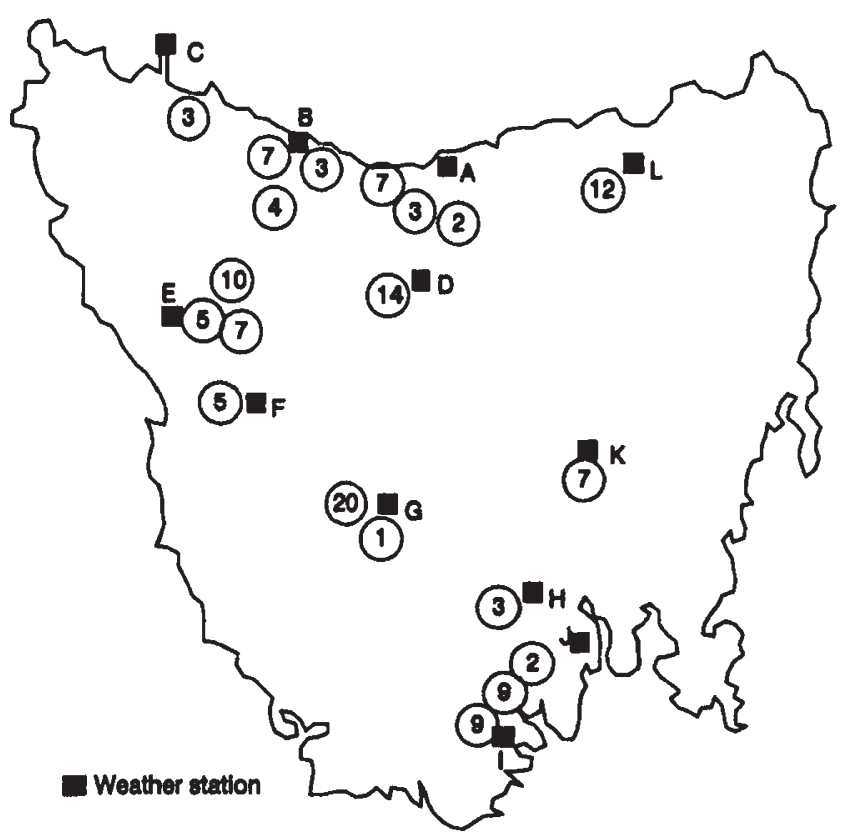

Fig. 1 Sites from which bees were collected, the nearest weather station and the seven regions used for analysis.

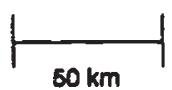

Numbers in the circles indicate the number of colonies sampled at that apiary or site. Elevation $(\mathrm{m})$ and long-term average monthly maximum and minimum temperatures $\left({ }^{\circ} \mathrm{C}\right)$ for each station are as follows:

Elevation Feb $T_{\min }$ Feb $T_{\max }$ July $T_{\min }$ July $T_{\max } \quad$ Region

$\begin{array}{lrrrrrl}\text { A. Devonport } & 12 & 12.4 & 21.6 & 4.1 & 12.4 & \text { North coast } \\ \text { B. Burnie } & 10 & 12.9 & 21.0 & 5.5 & 12.5 & \text { North coast } \\ \text { C. Stanley } & 10 & 12.9 & 20.6 & 6.5 & 12.0 & \text { North coast } \\ \text { D. Deloraine* } & 253 & 10.3 & 22.3 & 1.5 & 10.5 & \text { (Commercial) } \\ \text { E. Rosebery } & 140 & 9.1 & 21.8 & 2.3 & 10.9 & \text { Tullah } \\ \text { F. Queenstown } & 129 & 8.4 & 22.0 & 2.3 & 11.6 & \text { Queenstown } \\ \text { G. Tarraleah } & 589 & 6.3 & 19.1 & 0.0 & 8.2 & \text { Tarraleah } \\ \text { H. New Norfolk } & 5 & 11.3 & 24.0 & 1.9 & 10.9 & \text { South coast } \\ \text { I. Geeveston } & 40 & 8.7 & 21.9 & 1.3 & 11.7 & \text { South coast } \\ \text { J. Kingston } & 52 & 10.7 & 21.9 & 2.4 & 12.5 & \text { South coast } \\ \text { K. Oatlands } & 400 & 8.6 & 21.9 & 1.1 & 9.4 & \text { Midlands } \\ \text { L. Launceston } & 170 & 10.2 & 23.0 & 2.3 & 10.8 & \text { Launceston }\end{array}$

*Commercial apiary not used in most analyses.

numerous in the area (L. Slater, personal communication). We therefore included bees from Mr Slater's apiary in the feral population for the analyses below.

A further 14 colonies were sampled from a commercial apiary as an example of typical commercial stock. Samples from the commercial apiary were of daughters of different queens.

\section{Mitochondrial DNA RFLPS}

Total nucleic acid was extracted from the thorax of one bee per colony in an adaptation of a cell lysis method outlined in Sambrook et al. (1989). Each thorax was ground in $350 \mu \mathrm{L}$ of GIT $(4.0 \mathrm{M}$ guanidinium thiocyanate, $0.1 \mathrm{M}$ Tris- $\mathrm{HCl}(\mathrm{pH} 7.5), 1$ per cent $b$ - 
mercaptoethanol) buffer until the solutions turned pale yellow. Homogenates were then left to lyse for $15 \mathrm{~min}$ on ice; $125 \mu \mathrm{L}$ of ice-cold $7.5 \mathrm{~m}$ ammonium acetate was then added, the tubes were inverted 10 times and placed on ice for $5 \mathrm{~min}$. Particulate matter was then precipitated by centrifugation $(1400 \mathrm{~g}$ for $10 \mathrm{~min}$ at $\left.4^{\circ} \mathrm{C}\right)$. Supernatants were pipetted into new tubes. To these new tubes, $200 \mu \mathrm{L}$ of phenol ( $\mathrm{pH} 7.5$ ) was added and the tubes gently inverted 50 times. Tubes were then centrifuged at $15000 \mathrm{~g}$ for $15 \mathrm{~min}$ to precipitate a viscous pellet. Pellets were removed using wide-bore pipette tips. The remaining solutions were extracted twice, first with $200 \mu \mathrm{L}$ chloroform/isoamyl alcohol (24:1), followed by pure chloroform. DNA was then precipitated in two volumes (about $600 \mu \mathrm{L}$ ) of ice-cold absolute ethanol, followed by resting at $-70^{\circ} \mathrm{C}$ for 15 min and centrifugation for $10 \mathrm{~min}$ at $15000 \mathrm{~g}\left(4^{\circ} \mathrm{C}\right)$. Supernatants were then discarded and the pellets rinsed in 70 per cent ethanol and resuspended in $1 \times$ TE buffer.

Aliquots $(15 \mu \mathrm{L})$ of total DNA preparations were digested with EcoRI according to the manufacturer's directions (Boehringer Mannheim, Sydney). These enzymes cleave honey bee mitochondrial DNA at specific sequences which produce patterns of restricted DNA considered to distinguish $A$. $m$. mellifera from $A$. m. ligustica/carnica type bees (Smith \& Brown, 1990; Sheppard et al., 1991). Digested DNA was electrophoresed in 1 per cent agarose gels at $60 \mathrm{~V}$ for $3 \mathrm{~h}$ and visualized by staining with ethidium bromide (Oldroyd et al., 1992).

\section{Protein electrophoresis}

Thoraces of 12 bees per colony were each ground in $100 \mu \mathrm{L}$ of water. These extracts were electrophoresed for $20 \mathrm{~min}$ on cellulose-acetate gels (Helena Laboratories, Beaumont, TX) at $200 \mathrm{~V}$ in a $0.08 \mathrm{M}$ TrisEDTA-maleic acid running buffer ( $\mathrm{pH}$ 8.2). Malate dehydrogenase isozymes (Sylvester, 1976) were visualized by coating gels with $6 \mathrm{~mL} 1$ per cent molten agar to which $0.6 \mathrm{~mL} 0.1 \mathrm{M}$ Tris- $\mathrm{HCl}(\mathrm{pH} 8.0), 0.4 \mathrm{~mL}$ each of $0.04 \mathrm{~m}$ nicotinamide adenine dinucleotide and $1 \mathrm{M}$ disodium malate ( $\mathrm{pH} 7.0$ ), and $0.2 \mathrm{~mL}$ each of $0.145 \mathrm{M}$ methyl-thiazole blue and $0.065 \mathrm{M}$ phenazine methosulphate had been added (Cornuet, 1979). Three alleles were scored as fast, medium and slow according to the amount of anodal migration. These alleles correspond to $M d h^{65}, M d h^{80}$ and $M d h^{100}$, respectively, of Sheppard \& Berlocher (1984). Where genotypes were ambiguous, they were rerun against known standards on the same gel. Although there are additional $M d h$ alleles in some populations (e.g. Badino et al., 1983; Sheppard \& Berlocher, 1984, 1985), they were not observed in this study.

\section{Morphology}

The standard character set for the USDA-ID (Rinderer et al., 1993) morphometric determination of honey bee race was measured on 10 bees from each colony. Reference data sets from $A . m$. mellifera and $A . m$. ligustica were obtained from N. Koeniger (Institut für Bienenkunde, Oberursel, Germany). From the 18 characters common to both data sets, a factorial discriminant analysis was performed (Oldroyd et al., 1992), which produced discriminant functions that were then used to classify the bees of the present collection as being more similar to the $A . m$. mellifera or $A$. $m$. ligustica reference specimens. A second discriminant analysis was performed on all 23 characters of the bees of Tasmania alone, to detect population subdivision at the morphological level.

\section{Environmental temperatures}

Mean temperature minima $\left(T_{\min }\right)$ and maxima $\left(T_{\max }\right)$ for the coldest (July) and warmest (February) months were obtained from the Australian Bureau of Meteorology for the nearest weather station to each collection site (Fig. 1).

\section{Results}

\section{Mitochondrial DNA}

After digestion with EcoRI, two different haplotypes were found, one characteristic of $A . m$. ligustical carnica and the other of $A$. m. mellifera (Smith \& Brown, 1990; Sheppard et al., 1991). The feral populations sampled were divided into seven groups according to geographical location and elevation (Fig. 1). The relative frequencies of the two EcoRI haplotypes for these seven groupings are given in Fig. 2. The mellifera haplotype was at highest frequency in populations at higher elevation at Queenstown and Tarraleah. The carnica/ligustica haplotype was at highest frequency in the commercial population whereas bees that were collected in coastal areas had an intermediate frequency of the two types. The proportion of haplotypes was significantly heterogeneous among the seven feral populations $\left(\chi_{6}^{2}=19.5, P=0.003\right)$.

The frequency of the mellifera haplotypes in the population of colonies closest to each of the weather stations in Fig. 1 was computed and normalized with an arcsine $\sqrt{ } X$ transformation as raw proportions data are not normally distributed (Steel \& Torrie, 1980). There was no significant correlation between haplotype frequency and elevation or temperature (Table 1), probably because of the high frequency of the carnical ligustica mitotype at Tullah. 
(a) Mitochondria

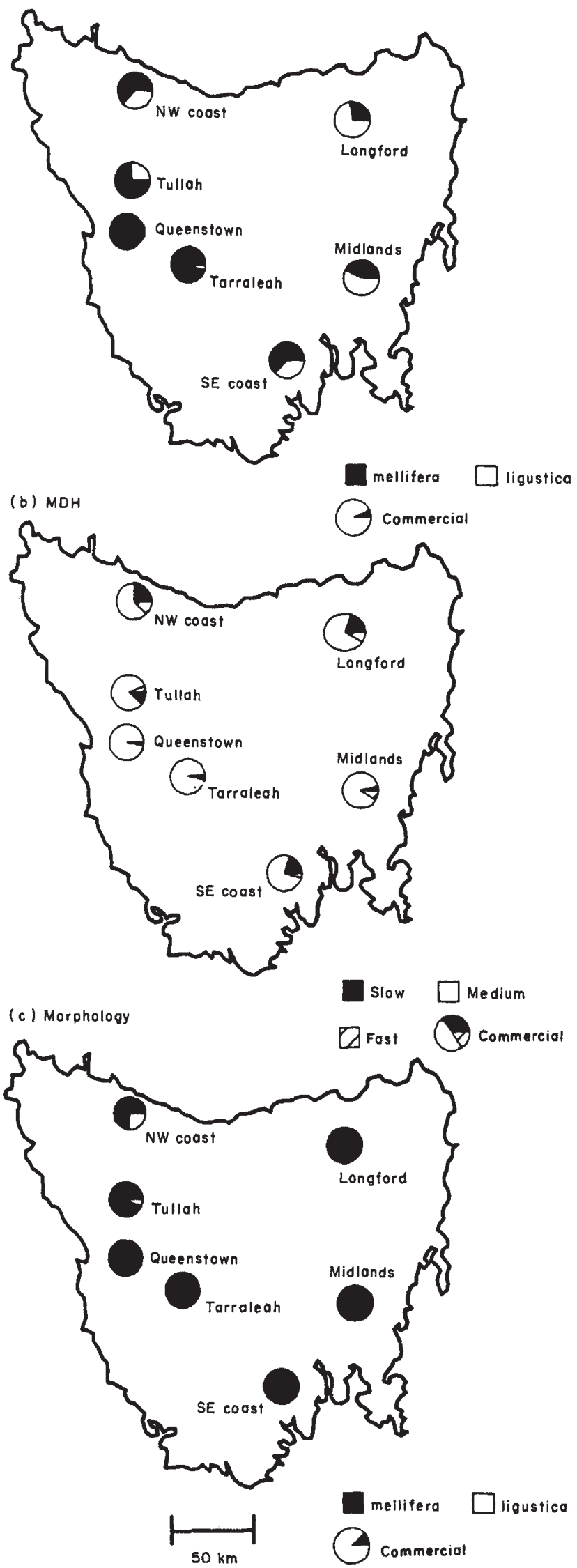

\section{Mdh allele frequencies}

All $M d h$ allele frequency data were normalized using an arcsine $\sqrt{ } X$ transformation before analysis of correlation or variance. The frequencies of the three $M d h$ alleles were heterogenous (slow allele $P=0.0001$, medium allele $P=0.0001$, fast allele $P=0.1$, ANOvA of the seven feral populations) over the island (Fig. 2). This heterogeneity was significantly associated with temperature (Table 1). The frequency of the medium allele was negatively correlated with temperature, the frequency of the slow allele positively correlated with temperature and the frequency of the fast allele was uncorrelated with temperature (Table 1). Slow and medium allele frequencies were also significantly correlated with elevation, which was significantly correlated with $T_{\min }$ and $T_{\max }$ in all months $(P<0.05)$.

When multiple tests of individual significance of correlation are performed, there is a danger of incorrectly declaring significance because of type I error. Therefore a sequential Bonferroni test (Rice, 1989) was performed on the correlations of Table 1. This test adjusts the probability that would be declared significant according to the number of simultaneous comparisons made. Because of the large number of correlations and low power of the test, this more conservative analysis did not reveal any significant correlations with an overall significance level of 5 per cent. Therefore, in a separate analysis, all environmental variables were combined into the first factor from a principal component analysis. By reducing the number of correlations examined simultaneously to five (Table 1) the type I error rate is reduced. The sequential Bonferroni test was performed on these five correlations and revealed that the slow allele frequency and the average discriminant score were significantly $(P<0.05)$ correlated with factor 1 . The medium allele frequency was only marginally significant $(P<0.1)$.

$M d h$ genotype frequencies were tested for departures from Hardy-Weinberg equilibrium for each of the seven feral and one commercial populations using the algorithm of Guo \& Thompson (1992) for Fisher's exact test. For this analysis, one bee was randomly selected from each colony. This avoids the bias created

Fig. 2 Distributions of mitochondrial haplotypes, $M d h$ genotypes and morphological phenotypes in the Apis mellifera population of Tasmania. (a) Proportions of queens carrying the mellifera and ligustica mitotypes as determined by restriction of mitochondrial DNA by EcoRI. (b) Relative frequencies of three alleles of $M d h-1$. (c) Proportions of colonies which are more similar to $A$. m. ligustica and $A$. $m$. mellifera reference specimens according to the discriminant functions of Oldroyd et al. (1992). 
Table 1 Correlation coefficients (with $P$ in brackets) for mean temperatures, elevation at the nearest weather station $(n=11)$ and factor 1 from a principal component factor analysis of all these environmental variables with $M d h$ allele frequency, mtDNA RFLP frequency and discriminant score (function of Oldroyd et al., 1992) for 114 honey bee colonies in Tasmania

\begin{tabular}{lcccccc}
\hline Genetic marker or measure & Factor 1 & Elevation & Feb $T_{\min }$ & Feb $T_{\max }$ & July $T_{\min }$ & July $T_{\max }$ \\
\hline Frequency of mellifera & -0.058 & 0.041 & -0.17 & -0.41 & 0.18 & 0.021 \\
mitochondria & $(0.86)$ & $(0.90)$ & $(0.61)$ & $(0.21)$ & $(0.60)$ & $(0.95)$ \\
Frequency of colonies & $0.73^{*}$ & 0.63 & -0.81 & 0.01 & -0.69 & -0.67 \\
classified as mellifera-like & $(0.01)$ & $(0.04)$ & $(0.003)$ & $(0.97)$ & $(0.01)$ & $(0.02)$ \\
by discriminant analysis & & & & & & \\
Frequency of slow & $0.77^{*}$ & -0.79 & 0.77 & 0.28 & 0.52 & 0.71 \\
Mdh allele & $(0.005)$ & $(0.004)$ & $(0.005)$ & $(0.39)$ & $(0.10)$ & $(0.01)$ \\
Frequency of medium & -0.66 & 0.61 & -0.75 & -0.19 & -0.48 & -0.57 \\
Mdh allele & $(0.03)$ & $(0.04)$ & $(0.007)$ & $(0.56)$ & $(0.13)$ & $(0.07)$ \\
Frequency of fast & 0.30 & -0.12 & 0.54 & -0.0008 & 0.35 & 0.13 \\
Mdh allele & $(0.38)$ & $(0.72)$ & $(0.08)$ & $(1.0)$ & $(0.29)$ & $(0.69)$ \\
\hline
\end{tabular}

*Significant correlation $(P<0.05)$ as determined by a sequential Bonferroni test (Rice, 1989) of correlations between factor 1 and the 5 genetic parameters.

by queen genotype in cases where several workers are sampled per hive. There were no significant departures from Hardy-Weinberg equilibrium for any subpopulation $(P>0.5)$ or overall $(P>0.99)$.

\section{Morphology}

Colonies were classified according to their disciminant score as being more similar to A. m. mellifera or A. $m$. ligustica reference collections using the discriminant function described in Oldroyd et al. (1992). Nearly all bees were more similar to $A$. $m$. mellifera reference specimens than to $A$. $m$. ligustica reference specimens. Only commercial bees and a few collections from the north coast area were more similar to ligustica reference specimens than to mellifera ones (Fig. 2).

No Tarraleah bees were classified as being more similar to the ligustica reference specimens, all being classified as being of the mellifera type (Fig. 3). These results suggest that the mellifera-type morphology is conserved in the Tarraleah bees. The commercial bees sampled appear to be predominantly ligustica, but with some overlap with the mellifera type.

A cross validation study was conducted to examine population subdivision on the eight (seven feral and one commercial) populations in Tasmania at the morphometric level. Each colony was held out of the analysis while a new discriminant analysis was computed, and the held-out colony was classified by the new function. These analyses showed that the feral populations could not be reliably separated by discriminant analysis, with an overall error rate of 42 per cent. Classification error rates for each population ranged from 19 to 83 per cent, suggesting homogeneity of the feral population in terms of morphology. The feral population is therefore quite homogeneous, although the Tarraleah population showed greatest separation from the commercial population on the basis of the Mahalanobis distance. Only the commercial bees showed reasonable separation from the other populations, and even here there was considerable overlap with some of the feral populations, with 13.3 per cent of commercial colony classifications being incorrect.

There were no significant individual correlations between any morphometric measurement and maximum temperatures in February (Table 2). No measures of wing size were significantly correlated with temperature or elevation. However, measures of appendage length (the leg measures; Table 2) showed significant negative individual correlation with February $\mathrm{T}_{\min }$, July $\mathrm{T}_{\max }$ and July $\mathrm{T}_{\min }$, namely legs were significant negative individual correlations with February $T_{\min }$, July $T_{\max }$ and July $T_{\min }$, namely legs were 2) showed a number of significant negative correlations with temperature, suggesting larger bees in cooler areas. When all individual correlations were considered with the sequential Bonferroni test, there were no significant correlations at the 5 per cent level (Table 2). Even when the environmental variables were combined into a single factor score, wax mirror width $\mathrm{B}$ was the only individual morphometric measure to be significantly correlated with the combined environmental variables.

\section{Associations among genetic markers}

Within the feral population (110 colonies analysed) there was no significant association between bees classified as being more mellifera or ligustica-like on 


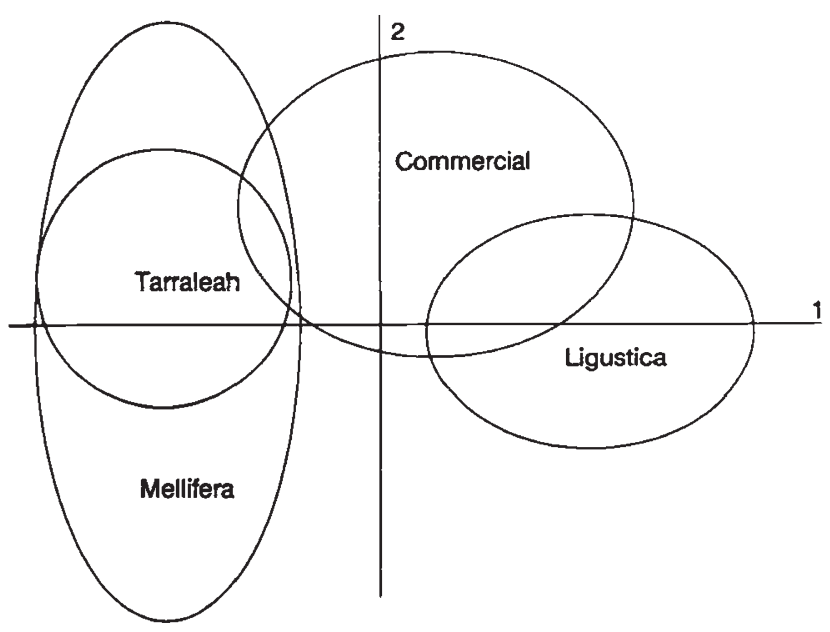

Fig. 3 Discriminant function analysis of the Tarraleah and commercial populations of Apis mellifera. Discriminant functions were produced from a discriminant analysis of $A$. $m$. ligustica and $A$. $m$. mellifera reference specimens from Europe (Oldroyd et al., 1992) and 95 per cent confidence ellipses drawn by the method of Cornuet (1982). The Tarraleah and commercial populations were then classified by this analysis. The Tarraleah population lies within the mellifera reference specimens whereas the commercial bees have evidence of hybridization between the two types.

the basis of morphology and their mitochondrial haplotype ( $P>0.25$, d.f. $=1, G$-test of homogeneity). However, there were strong associations between discriminant score and colony frequency of the three $M d h$ alleles (fast allele, $r=-0.41, P<0.001 ;$ medium, $r=0.60, P<0.001$; slow, $r=-0.53, P<0.0001$ ).

A nonrandom association of mtDNA and allozyme genotypes exists across the island (Table 3). Asmussen et al. (1987) provide statistics to partition such disequilibrium between nuclear and mtDNA markers to make inferences about the process of hybridization between two subspecies. They define an allelic disequilibrium $(D)$ which measures overall associations between the nuclear and mtDNA genotypes, and three genotypic disequilibria $\left(D_{1}, D_{2}, D_{3}\right)$ which correspond to associations between two mtDNA genotypes, and three nuclear genotypes. We computed these $D$ statistics after pooling the fast and slow alleles (Table 4). Again, there were highly significant associations between the nuclear and mtDNA markers $(P=0.0042$, Fisher's exact test $)$. Examination of the $D$ values reveals that in homozygous medium individuals, there was a higher than expected frequency of the mellifera mitotype whereas in heterozygous medium individuals, there was a lower than expected frequency of the mellifera mitotype.

\section{Discussion}

Of the parameters measured, the best overall measure of racial type is morphology because of the variety and extremely high heritability of the characters used (Oldroyd et al., 1991). According to this criterion, the feral bees of Tasmanian appear strongly mellifera-like in the cooler regions at Queenstown and Tarraleah, and more lugustica-like in warmer north-coastal regions (Fig. 2). The commercial bees sampled were more ligustica-like than mellifera-like in their morphology (Fig. 2) and all other measures (Figs 2 and 3). The distribution of mitochondrial DNA haplotypes and $M d h$ allele frequencies suggest that hybridization between $A . m$. mellifera and $A$. m. ligustica is extensive, particularly in coastal areas. The mating biology of the species and the fact that all subpopulations were in Hardy-Weinberg proportions suggest that all populations were random mating. At Queenstown and Tarraleah, there is only a slight influence of ligustica genotypes as revealed by low mt-DNA and $M d h$ markers normally associated with $A$. $m$. ligustica, and the significant $D$ values (Table 4).

This heterogeneity in the population is not caused by physical separation of coastal and highland populations. The major honey-producing areas of Tasmania are in the western highlands (the Queenstown and Tullah sample sites are within this area), and tens of thousands of commercial bee colonies are moved into the area for summer production. Thus although the commercial colonies are moved in after the swarming season, large numbers of ligustica-type drones are present in the area every year, providing the opportunity for hybridization. Given that Africanized bees were able to spread through south and central America at the rate of $200-400 \mathrm{~km}$ per year (Taylor, 1977), the 100 years of active propagation of ligustica-type bees by apiarists would seem enough time for ligustica alleles to become widely spread across the $300 \mathrm{~km}$ long island unless there are genetic impediments to that spread.

We conclude that $A$. m. mellifera and A. m. ligustica form hybrids which have fitness equal to or greater than that of the parents in coastal environments. Gene flow occurs between the commercial, predominantly ligustica population into the feral, predominantly mellifera population on the coast, but is restricted in cooler regions where there is a very large feral population of $A$. m. mellifera. We speculate that the fitness of A. $m$. ligustica and ligustica/mellifera hybrids is lower than that of 'pure' $A$. m. mellifera in cooler regions. There is some exchange of selectively neutral mitochondria between the populations, but less movement of the $M d h$ alleles which may not be selectively neutral in different climates (Nielson et al., 1994; Cornuet et 
Table 2 Correlation coefficients (with $P$ in brackets) for mean temperatures, elevation at the nearest weather station $(n=11)$ and factor 1 from a principal component factor analysis of all these environmental variables with various morphometric measures defined by Rinderer et al. (1993)

\begin{tabular}{lcccccc}
\hline & Factor 1 & Elevation & Feb $T_{\min }$ & Feb $T_{\max }$ & July $T_{\min }$ & July $T_{\max }$ \\
\hline Forewing length & -0.400 & 0.494 & -0.317 & -0.213 & -0.076 & -0.511 \\
& $(0.22)$ & $(0.12)$ & $(0.34)$ & $(0.53)$ & $(0.82)$ & $(0.11)$ \\
Forewing width & -0.480 & 0.551 & -0.480 & -0.433 & -0.113 & -0.462 \\
& $(0.13)$ & $(0.08)$ & $(0.13)$ & $(0.18)$ & $(0.74)$ & $(0.15)$ \\
Hindwing length & -0.028 & 0.113 & -0.057 & -0.328 & 0.357 & -0.105 \\
& $(0.93)$ & $(0.74)$ & $(0.87)$ & $(0.32)$ & $(0.28)$ & $(0.76)$ \\
Hindwing width & 0.165 & -0.077 & 0.193 & -0.217 & 0.374 & 0.111 \\
& $(0.63)$ & $(0.82)$ & $(0.57)$ & $(0.52)$ & $(0.26)$ & $(0.74)$ \\
Cubital vein B & -0.698 & 0.648 & -0.741 & -0.123 & -0.575 & -0.646 \\
& $(0.02)$ & $(0.03)$ & $(0.009)$ & $(0.72)$ & $(0.06)$ & $(0.03)$ \\
Cubital vein A & 0.657 & -0.506 & 0.784 & -0.020 & 0.748 & 0.508 \\
& $(0.03)$ & $(0.11)$ & $(0.004)$ & $(0.95)$ & $(0.008)$ & $(0.11)$ \\
Tibia length & -0.713 & 0.666 & -0.761 & 0.035 & -0.661 & -0.659 \\
& $(0.01)$ & $(0.02)$ & $(0.006)$ & $(0.92)$ & $(0.03)$ & $(0.03)$ \\
Femur length & -0.568 & 0.507 & -0.594 & 0.163 & -0.558 & -0.593 \\
& $(0.07)$ & $(0.11)$ & $(0.05)$ & $(0.63)$ & $(0.07)$ & $(0.05)$ \\
Basitarsis length & -0.123 & 0.200 & -0.101 & 0.144 & -0.116 & -0.118 \\
Basitarsis width & $(0.72)$ & $(0.55)$ & $(0.77)$ & $(0.67)$ & $(0.73)$ & $(0.73)$ \\
& -0.020 & 0.128 & -0.037 & 0.096 & 0.175 & -0.107 \\
Sternite length & $(0.95)$ & $(0.71)$ & $(0.91)$ & $(0.78)$ & $(0.61)$ & $(0.75)$ \\
& -0.409 & 0.362 & -0.387 & 0.098 & -0.280 & -0.570 \\
Wax mirror length & $(0.21)$ & $(0.27)$ & $(0.24)$ & $(0.77)$ & $(0.40)$ & $(0.07)$ \\
& -0.394 & 0.376 & -0.416 & -0.027 & -0.223 & -0.466 \\
Wax mirror width A & $(0.23)$ & $(0.25)$ & $(0.20)$ & $(0.93)$ & $(0.51)$ & $(0.15)$ \\
& -0.681 & 0.658 & -0.620 & 0.158 & -0.667 & -0.734 \\
Wax mirror width B & $(0.02)$ & $(0.03)$ & $(0.04)$ & $(0.64)$ & $(0.02)$ & $(0.01)$ \\
& $0.775 *$ & -0.638 & 0.879 & 0.119 & 0.796 & 0.614 \\
& $(0.005)$ & $(0.034)$ & $(0.0004)$ & $(0.73)$ & $(0.003)$ & $(0.04)$ \\
\hline
\end{tabular}

*Significant $(P<0.05)$ correlation as determined by a sequential Bonferroni test (Rice, 1989) of correlations between factor 1 and the 12 morphometric measures.

Table 3 Association of mtDNA genotypes with allozyme genotypes for 109 feral colonies of honey bees in Tasmania $\dagger$

\begin{tabular}{lcc}
\hline & $\begin{array}{c}\text { Observed (and expected) numbers } \\
\text { of mt-DNA genotypes } \ddagger\end{array}$ \\
\cline { 2 - 3 } Mdh genotype & mellifera & ligustica \\
\hline Slow/slow & $0(0.68)$ & $1(0.31)$ \\
Slow/medium & $10(13.76)$ & $10(6.23)$ \\
Slow/fast & $1(2.75)$ & $3(1.24)$ \\
Medium/medium & $58(51.6)$ & $17(23.39)$ \\
Medium/fast & $5(6.19)$ & $4(2.81)$ \\
Fast/fast\$ & - & - \\
\hline
\end{tabular}

$\dagger$ The probability of observing a table with at least this much association (Fisher's exact test) is $\mathbf{0 . 0 1 8 .}$

łExpected frequencies computed from observed populationwide frequencies.

$\S$ Fast/fast genotype absent from this sample. al., 1994). This, therefore, is an example of secondary contact where fitness is affected by an environmental gradient.

What do our Tasmanian results reveal about the honey bee populations of Europe, the original home of $A$. $m$. mellifera and A. $m$. ligustica, and the hybrid zones between these subspecies? Clearly, the bees of Tasmania have established a similar population structure to their ancestors in Europe. One is tempted to suggest that the population has subdivided in Tasmania in parallel with similar environments in Europe. This scenario fits well with the situation in the mountains of northern Italy, but does not explain the hybrid zone between ligustica and mellifera on the temperate Ligurian coast where there is little or no temperature gradient across the hybrid zone, at least along the coast.

Hybrid zones which are the result of recent contact should broaden over time as there is an exchange of 
Table 4 Genotypic frequencies (expected $\dagger$ ) and cytonuclear disequilibria between $M d h$ and mtDNA genotypic frequencies for 109 feral honeybee colonies in Tasmania

\begin{tabular}{|c|c|c|c|c|}
\hline & \multicolumn{3}{|c|}{$M d h$ genotypic frequencies $\S$} & \\
\hline & $A A$ & $A B$ & $B B$ & \\
\hline \multicolumn{5}{|l|}{ mtDNA } \\
\hline mellifera & $2(2.75)$ & $15(21.33)$ & $58(50.9)$ & \\
\hline ligustica & $2(1.25)$ & $16(9.67)$ & $16(23.08)$ & \\
\hline \multicolumn{5}{|c|}{ Disequilibria $\ddagger \pm \mathrm{SE}$} \\
\hline & $\begin{array}{c}D_{1} \\
-0.069 \pm 0.096\end{array}$ & $\begin{array}{c}D_{2} \\
-0.058 \pm 0.021 *\end{array}$ & $\begin{array}{c}D_{3} \\
0.065 \pm 0.022^{*}\end{array}$ & $\begin{array}{c}D \\
0.035 \pm 0.012^{*}\end{array}$ \\
\hline
\end{tabular}

$\dagger$ Expected frequencies computed from population frequencies of mtDNA types. $\ddagger D$ values computed according to Asmussen et al. (1987).

$\S A$, slow + fast $; B$, medium.

*Significantly different from $0(P<0.05)$.

genes between the two populations (Barton \& Hewitt, 1985). In the absence of fitness differences, the width of such zones should increase proportionally to the number of generations, $G$, since contact and the variance of the dispersal distance of the subject organism per generation, $\sigma^{2}$, such that $W$, the width of the cline, is given by:

$$
W=\sqrt{ }(G 2 \pi / \sigma)
$$

(rearranged from Barton \& Hewitt, 1985).

If we assume contact between $A$. m. mellifera and $A$. $m$. ligustica approximately 10000 years ago (after the last glaciation), then $G=$ about 10000 . If honey bee swarms disperse at 0-2 $\mathrm{km}$ per generation (Lindauer, 1961 ), then $\sigma$ is probably about 1 . According to eqn 1 an approximately $250 \mathrm{~km}$ wide hybrid zone should exist between the two subspecies in Europe. This fits fairly well with the observed width (Cornuet, 1983; Badino et al., 1983, 1984, 1988a,b; Comparini \& Biasiolo, 1991; Nazi, 1992; Meixner et al., 1993), but cannot explain the apparent racial admixture in Tasmania, where there is artificial mixing of genotypes by beekeepers.

Alternative hypotheses to explain hybrid zones relate to hybrid dysfunction or superiority in the narrow environment of the tension zone. Harrison \& Hall (1993) suggested that incompatibilities between mitochondria and cytoplasm in the European and African bees might reduce hybridization between European and Africanized populations. A mechanism such as this is required for the formation of a 'tension zone' (Barton \& Hewitt, 1985). Our data show that such a mechanism is not operating in Tasmania. Even at the coldest, most isolated site (Tarraleah) the ligustica mitotype was identified in a colony that was strongly mellifera-like in terms of morphology and Mdh allele frequency. Such colonies can only exist after repeated generations of backcrossing and should be eliminated if a significant incompatibility exists between ligustica mitochondria and the mellifera nuclear genome (Rinderer et al., 1991).

Inter-racial crosses between honey bees generally result in increased fitness in $\mathrm{F}_{1} \mathrm{~s}$ (Cale \& Gowen, 1956; Ruttner, 1968; Oldroyd et al., 1985). Therefore hybrid depression in a tension zone is unlikely to impede gene flow between these subspecies. Thus we can eliminate both popular explanations of hybrid zones (recent contact and hybrid dysfunction; Hewitt, 1988) for the apparent clines between $A . m$. mellifera and $A . m$. ligustica in Tasmania.

Restriction of gene flow between populations may also result from assortative mating. Koeniger et al. (1989) found assortative mating between $A . m$. ligustica and $A$. m. carnica in the Austrian Alps. We hypothesize that mellifera drones and queens will fly in cooler weather than ligustica-type drones and queens, at least in Tasmania. This would reduce inter-racial mating in cooler areas, but allow hybridization in the coastal areas. If this hypothesis is correct, then the maintenance of the zones of hybridization and the lack of gene flow between A. m. carnica, A. m. ligustica and A. m. mellifera in the European Alps may be explained by this same phenomenon.

Nielson et al. (1994) demonstrated that on three continents, the frequency of the Mdh fast allele is positively correlated with average environmental temperature, the frequency of the medium allele negatively correlated with temperature and the frequency of the slow allele only weakly correlated with temperature. In contrast, we found only a weak negative corre- 
lation between temperature and medium allele frequency, but a significant correlation with frequency of the slow allele. Nielson et al. (1994) argued that the existence of parallel clines for $M d h$ relative allele frequency associated with environmental temperature in Spain, Brazil and California is strong evidence for direct selection on the allelic forms. Cornuet et al. (1994) demonstrated differing in vitro thermostabilities of the allelic forms thus suggesting a mechanism by which selection could act to develop such clines. Our results also show that $M d h$ allele frequency and discriminant scores are correlated with environmental temperature in Tasmania (Tables 1 and 2). However, this is not evidence for direct selection on allelic frequency or the lengths and sizes of various appendages. Rather, our correlations seem to result from an abrupt change from the mellifera-type on the highland sites to a hybridized ligustica-type on the (particularly northern) coast. This explanation accounts for the correlation of discriminant score with environmental variables that must otherwise be explained by selection, which seems unlikely (Rinderer et al., 1991). But, the lack of a selectively based cline for the medium allele in Tasmania does not preclude the existence of such clines within racial groups elsewhere. However, at least in Brazil, Italy and Spain, the clines may be equally explained by competitive displacement of racial types.

Finally, our morphological and molecular data support the findings of Ruttner (1976) which suggest that the Tarraleah population is a well preserved population of $A$. mellifera mellifera, having only a weak genetic component derived from other sources.

\section{Acknowledgements}

We thank all the beekeepers who allowed us access to their hives, H. Ayton, former apiary inspector, for guidance on our collecting trip, and S. Koulianos for assistance on that trip. R. Whiteside performed the morphometric measurements. The computer program GENEPOP by M. Raymond and F. Rousett was used to compute the Hardy-Weinberg equilibrium probabilities, and the $D$ statistics were computed with a program provided by J. Arnold. S. Buco, A. Stelzer and L. Jermiin assisted with some of the statistical computations. We thank S. Sheppard, A. Poiani, S. Lawler and the referees for comments on the manuscript. Voucher specimens are lodged at the USDA Honey-Bee Breeding Laboratory, Baton Rouge, accession numbers 11923-12054. This research was supported by the Australian Research Council, and the Honey Bee Research and Developmental Council. T.E.R.'s contribution is in cooperation with the Louisiana Agricultural Experiment Station.

\section{References}

ARNOLD, J. 1993. Cytonuclear disequilibria in hybrid zones. Ann. Rev. Ecol. Syst., 24, 521-554.

ASSMUSSEN, M. A., ARNOLD, J. AND AVISE, J. C. 1987. Definition and properties of disequilibrium statistics for associations between nuclear and cytoplasmic genotypes. Genetics, 115, 775-768.

AYTON, н. 1977. The black bees of Tarraleah. In: Harnaj, V., Doull, K. and Harnaj, A. (eds) XXVI International Congress of Apiculture, pp. 266-268. Apimondia Publishing House, Bucharest.

badino, G., CElebrano, G. AND manino, A. 1983. Population structure and $M D H-1$ locus variation in Apis mellifera ligustica. J. Hered., 74, 443-446.

Badino, G., CElebrano, G. AND manino, A. 1984. Population genetics of Italian honeybee (Apis mellifera ligustica Spin.) and its relationships with neighbouring subspecies. Bol. Mus. Reg. Sci. Nat. Torino, 2, 571-584.

Badino, G., Celebrano, G., manino, A. AND ifantidus, M. D. 1988a. Allozyme variability in Greek honey bees (Apis mellifera L.) Apidologie, 19, 377-386.

BADINo, G., CElebrano, G. AND MANINo, A. 1988b. Genetica di popolazione delle sottospecie mediterranee di Apis mellifera L. sulla base di varianti alloenzimatiche. Apicult. Mod., 79, 233-239.

BARTON, N. H. AND HEWITT, G. M. 1985. Analysis of hybrid zones. Ann. Rev. Ecol. Syst., 16, 113-148.

BAZYKIN, A. D. 1969. A hypothetical mechanism of speciation. Evolution, 23, 685-687.

CALE, G. H. AND GOWEN, J. w. 1956. Heterosis in the honey bee (Apis mellifera L.) Genetics, 41, 292-303.

COMPARINI, A. AND BIASIOLO, A. 1991. Genetic discrimination of Italian bee Apis mellifera ligustica from Carniolan bee, Apis mellifera carnica by allozyme variability analysis. Bio. Syst. Ecol., 19, 189-194.

CORNUET, J.-M. 1979. The MDH system of the honey bees of Guadaloupe. J. Hered., 70, 223-224.

CORNUET, J.-M. 1982. Représentation graphique de populations multinormales par des ellipses de confiance. Apidologie, 13, 15-20.

CORNUET, J.-M. 1983. Reproduction génétique et sélection de l'abeille. Bull. Tech. Apic., 10, 13-36.

CORNUET, J.-M., OLDROYD, B. P. AND CROZIER, R. H. 1994. Unequal thermostability of allelic forms of malate dehydrogenase in honey bees. J. Apic. Res. (in press).

DALY, H. V., HOELMER, K. AND Gambino, P. 1991. Clinal geographic variation in feral honey bees in California, USA. Apidologie, 22, 591-607.

ENDLER, J. A. 1977. Geographic Variation, Speciation and Clines. Princeton University Press, Princeton, New Jersey.

GARNERY, L. 1992. Variabilité de l'ADN mitochondrial de l'abeille domestique implications phylogénétiques. Ph.D. Thesis, Université de Paris.

GARNERY, L., CORNUET, J.-M. AND SOLINAC, M. 1992. Evolutionary history of the honey bee Apis mellifera inferred from mitochondrial DNA analysis. Mol. Ecol., 1, 145-154.

GUO, S. W. AND THOMPSON, E. A. 1992. Performing an exact test of Hardy-Weinberg proportion for multiple alleles. Biometrics, 48, 361-372. 
HARRISON, J. F. AND HALL, H. G. 1993. African-European honeybee hybrids have low nonintermediate metabolic capacities. Nature, 363, 258-260.

HEWITT, G. M. 1988. Hybrid zones: natural laboratories for evolutionary studies. Trends Ecol. Evol., 3, 158-167.

KOENIGER, G., KOENIGER, N., PECHHACKER, H., RUTTNER, F. AND BERG, s. 1989. Assortative mating in a mixed population of European honeybees, Apis mellifera ligustica and Apis mellifera carnica. Ins. Soc., 36, 129-138.

lindauer, M. 1961. Communication Among Social Bees. Harvard University Press, Cambridge, MA.

MEIXNER, M. D., SHEPPARD, W. S. AND POKLUKAR, J. 1993. Asymmetrical distribution of a mitochondrial DNA polymorphism between two introgressing honey bee species. Apidologie, 24, 147-153.

MOORE, w. S. 1977. An evaluation of narrow hybrid zones in vertebrates. Quart. Rev. Biol., 52, 263-277.

MOORE, W. S. AND BUCHANAN, D. B. 1985. Stability of the northern flicker hybrid zone in historical times: implications for adaptive speciation theory. Evolution, 39, 135-151.

NAZI, F. 1992. Morphometric analysis of honey bees from an area of racial hybridization in northeastern Italy. Apidologie, 23, 89-96.

NIELSON, D., PAGE, R. E. AND CROSLAND, M. W. J. 1994. Clinal variation and selection of $\mathrm{MDH}$ allozymes in honey bee populations. Experientia, 50, 867-871.

OLDROYD, B. P., MORAN, C. AND NICHOLAS, F. W. 1985. Diallel crosses of honey bees. 1. Genetic analysis of honey production using a fixed effects model. J. Apic. Res., 24, 243-249.

OLDROYD, B. P., RINDERER, T. E. AND BUCO, S. M. 1991. Heritability of morphological characters used to distinguish European and Africanized honeybees. Theor. Appl. Genet., 82, 499-504.

OLDROYD, B. P., SHEPPARD, W. S. AND STELZER, J. A. 1992. Genetic characterisation of the bees of Kangaroo Island, South Australia. J. Apic. Res., 31, 141-148.

RICE, W. R. 1989. Analysing tables of statistical tests. Evolution, 43, 223-225.

RINDERER, T. E., STELZER, J. A., OLDROYD, B. P., BUCO, S. M. AND RUBINK, W. L. 1991. Hybridization between European and Africanized honey bees in the neotropical Yucatan Peninsula. Science, 253, 309-311.
RINDERER, T. E., BUCO, S. M., RUBINK, W. L., DALY, H. V., STELZER, J. A., RIGGIO, R. M. AND BAPTISTA, F. C. 1993. Morphometric identification of Africanized and European honey bees using large reference populations. Apidologie, 24, 569-585.

RUTTNER, F. 1968. Methods of breeding honey bees: intraracial selection or inter-racial hybrids? Bee World, 49, 66-72.

RUTTNER, F. 1976. Isolated populations of honeybees in Australia. J. Apic. Res., 15, 97-104.

RUTTNER, F. 1988. Biogeography and Taxonomy of Honeybees. Springer, Berlin.

RUTTNER, F., TASSENCOURT, L. AND LOUVEAUX, J. 1978. Biometrical-statistical analysis of the geographical variability of Apis mellifera L. Apidologie, 9, 363-381.

SAMBROOK, J., FRITSCH, E. F. AND MANIATIS, T. 1989. Molecular Cloning: A Laboratory Manual. Cold Spring Harbor Laboratory Press, Cold Spring Harbor, NY.

SHEPPARD, W. S., RINDERER, T. E., MAZZOLI, J. A., STELZER, J. A. AND SHIMANUKI, H. 1991. Gene flow between African- and European-derived honey bee populations in Argentina. Nature, 349, 782-784.

SHEPPARD, w. S., AND BERLOCHER, s. H. 1984. Enzyme polymorphism in Apis mellifera from Norway. J. Apic. Res., 23, 64-69.

SHEPPARD, W. S. AND BERLOCHER, s. H. 1985. New allozyme variability in Italian honey bees. J. Hered., 76, 45-85.

SMITH, D. R. 1991. African bees in the Americas: insights from biogeography and genetics. Trends Ecol. Evol., 6, 17-21.

SMITH, D. R. AND BROWN, W. M. 1990. Restriction endonuclease cleavage site and length polymorphisms in mitochondrial DNA of Apis mellifera mellifera and A. $m$. carnica (Hymenoptera: Apidae). Ann. Ent. Soc. Am., 83, 81-88.

STEEL, R. D. G. AND TORRIE, J. H. 1980. Principles and Procedures of Statistics, 2nd edn. McGraw-Hill Kogakusha, Tokyo.

SYlVESTER, H. A. s. 1976. Allozyme Variation in Honeybees (Apis mellifera). Ph.D. Thesis, University of California at Davis.

TAYLOR, O. R. 1977. The past and possible future spread of Africanized honeybees in the Americas. Bee World, 58, $38-47$ 